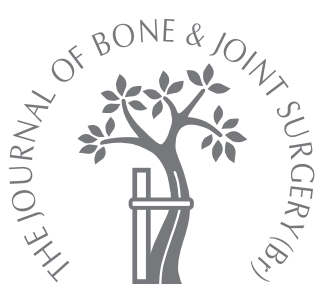

P. N. Baker,

F. M. Khaw,

L. M. G. Kirk,

C. N. A. Esler,

P. J. Gregg

From the James Cook

University Hospital,

Middlesbrough,

England

- P. N. Baker, MBBS, MRCS,

MSc, Specialist Trainee in

Trauma and Orthopaedics

I. J. Gregg, MD, FRCS,

FRCS(Ed), Consultant

Orthopaedic Surgeon, Professor

of Orthopaedic Surgical Science

South Tees Hospitals NHS Trust,

The James Cook University

Hospital, Marton Road,

Middlesbrough, Cleveland TS4

3BW, UK.

E. M. Khaw, MD, FRCS,

Fellow of the Faculty of Public Health, Consultant in Health

Protection, Honorary Clinical

Senior Lecturer in Public Health

Institute of Heath and Society

The Medical School, Newcastle

University, Framlington Place,

Newcastle upon Tyne NE2 4HH,

UK.

I. M. G. Kirk, BSc, MCSP,

Senior Research

Physiotherapist

Freeman Road Hospital,

Freeman Road, High Heaton,

Newcastle upon Tyne NE7 7DN

UK.

In C. N. A. Esler, BMedSci(Hons), FRCS(Tr \& Orth), Consultant

Orthopaedic Surgeon, Honorary

Senior Lecturer

University Hospitals of Leicester,

Glenfield Hospital, Groby Road,

Leicester LE3 9QP, UK.

Correspondence should be sent

to $\mathrm{Mr}$ P. N. Baker; e-mail:

drpnbaker@hotmail.com

C2007 British Editorial Society of Bone and Joint Surgery

doi:10.1302/0301-620X.89B12.

$19363 \$ 2.00$

$J$ Bone Joint Surg [Br] 2007;89-B:1608-14.

Received 26 February 2007;

Accepted after revision 17

August 2007

\title{
A randomised controlled trial of cemented versus cementless press-fit condylar total knee replacement
}

\author{
15-YEAR SURVIVAL ANALYSIS
}

We report the long-term survival of a prospective randomised consecutive series of 501 primary knee replacements using the press-fit condylar posterior cruciate ligamentretaining prosthesis. Patients received either cemented (219 patients, 277 implants) or cementless (177 patients, 224 implants) fixation. Altogether, 44 of 501 knees (8.8\%) underwent revision surgery (24 cemented vs 20 cementless). For cemented knees the 15year survival rate was $\mathbf{8 0 . 7 \%}(95 \%$ confidence interval (CI) 71.5 to 87.4$)$ and for cementless knees it was $75.3 \%(95 \% \mathrm{Cl} 63.5$ to 84.3$)$. There was no significant difference between the two groups (cemented vs cementless; hazard ratio (HR) $0.83,95 \% \mathrm{Cl} 0.45$ to $1.52, p=0.55)$. When comparing the covariates there was no significant difference in the rates of survival between the side of operation (HR $0.58, p=0.07$ ), age (HR $0.97, p=0.10$ ) and diagnosis (HR $1.25 \mathrm{p}=\mathbf{0 . 7 2}$ ). However, there was a significant gender difference, with males having a higher failure rate with cemented fixation (HR 2.48, $p=0.004$ ). Females had a similar failure rate in both groups.

This single-surgeon series, with no loss to follow-up, provides reliable data of the revision rates of one of the most commonly-used total knee replacements. The survival of the press-fit condylar total knee replacement remained good at 15 years, irrespective of the method of fixation.

There are currently 33 different types of total condylar knee prosthesis being implanted in England and Wales. ${ }^{1}$ According to the National Joint Registry's database, in addition, ten types of unicondylar prosthesis, three types of patellofemoral replacement prosthesis and seven different hinged prostheses are in contemporary use. It is imperative that surgeons know the long-term outcome and possibility of survival for the wide variety of implants they are using. Such information may also be useful for health-care commissioners in modelling the future provision of revision knee surgery.

Some previous reports comparing cemented and cementless fixation for knee replacement have suggested that both clinical outcome and long-term survival are inferior for cementless prostheses. $^{2-5}$ However, these studies were not randomised and had methodological flaws, which may account for the differences seen.

Previously, we published a ten-year survival analysis of a prospective randomised trial comparing cemented and cementless fixation of press-fit condylar (PFC) primary total knee replacement $(\mathrm{TKR})^{6}$ which showed good survival at ten years irrespective of the method of fixation. We now present a longer term analy- sis of this cohort, comparing the survival over a 15 -year period.

\section{Patients and Methods}

Between June 1987 and February 1997, all patients requiring primary TKR using the PFC posterior cruciate ligament (PCL)-retaining knee replacement system (Johnson \& Johnson Professional Inc., Raynham, Massachussetts) under the care of the senior author (PJG) were recruited into a randomised controlled trial in order to compare cemented and cementless fixation. Inclusion in the trial depended on the patient's suitability for both methods of fixation to be used, so that the choice of implant could be randomised during the operation only after the bone surfaces had been prepared. Before March 1993, randomisation according to year of birth was carried out for 320 implants, with allocation into each of the two groups depending upon whether their year of birth ended in an odd or an even number. After March 1993, a more satisfactory method of randomisation ${ }^{7}$ using computer-generated random numbers was used for 181 implants.

A total of 28 patients undergoing singlestage bilateral TKR and 77 of 81 patients 
Table I. Reasons for exclusion from randomisation for cemented or cementless press-fit condylar total knee replacement

\begin{tabular}{ll}
\hline Number of implants & Reason for non-randomisation \\
\hline 45 & Grossly porotic bone or bone defects not requiring grafting \\
18 & Bone cuts not sufficiently accurate for a cementless prosthesis \\
15 & Bone defects sufficiently large to warrant bone grafting \\
6 & Error of randomisation \\
5 & Consent not provided \\
4 & Prosthesis unavailable \\
3 & Jehovah's witness \\
2 & Patient on therapeutic anticoagulation following previous cerebrovascular accident \\
\hline
\end{tabular}

Table II. Details of the patients

\begin{tabular}{lcc}
\hline & Cemented & Cementless \\
\hline Patients (TKRs)* & 219 (277) & 177 (224) \\
Gender & & \\
$\quad$ Male & 98 & 74 \\
$\quad$ Female & 121 & 103 \\
& & \\
Diagnosis & 199 & 163 \\
$\quad$ Osteoarthritis & 17 & 13 \\
$\quad$ Rheumatoid arthritis & 3 & 1 \\
$\quad$ Other & 70 (41 to 87) & 71 (49 to 88) \\
Mean age in yrs (range) & & \\
* TKRs, total knee replacements
\end{tabular}

undergoing bilateral staged TKR had the same method of fixation on both sides. The other four patients with bilateral TKRs had a cemented implant in one knee and cementless in the other.

Of a consecutive total of 599 TKRs (481 patients), 98 knees (85 patients) were excluded for reasons given in Table I. Jehovah's witnesses and patients on anticoagulation were excluded, as it was the senior author's experience that cementless TKRs tended to have a greater blood loss than cemented knees. He therefore preferred to perform cemented TKR in these patients. Thus, 501 TKRs $(396$ patients) were studied, with 277 cemented (219 patients) and 224 cementless (177 patients). Details of the patients are given in Table II.

All TKRs were carried out by, or under the direct supervision of, the senior author. The TKR used is a modular prosthesis with a cobalt-chrome femoral component articulating with a polyethylene insert which is mounted on a titanium tibial tray with a cruciform stem. Both the cemented and the cementless implants have the same geometry and are introduced using the same instrumentation. Cementless implants have a coating of porous beads for contact with the bone cuts, and were not hydroxyapatitecoated.

A standard surgical technique was used, with a longitudinal incision and a medial parapatellar approach. The bone was prepared using the manufacturer's cutting guides. In most knees the PCL was left intact, but in a few with a severe fixed-flexion deformity it was released from the posterior aspect of the tibia and a cruciate-sparing tibial component was used. A polyethylene insert with a thickness of at least $8 \mathrm{~mm}$ was routinely used, but one of $10 \mathrm{~mm}$ thickness was occasionally required to achieve stability.

In the cemented group, the components were implanted using cement of normal viscosity. This was layered over the proximal tibia by hand and inserted into the recess for the stem of the prosthesis. Cement was applied to the back of the femoral component except for the anterior chamfer and flange. In these regions cement was applied directly on to the bone. The knee was held in extension until the cement had polymerised. The patella was not resurfaced. The knee was immobilised in a Robert Jones bandage ${ }^{8}$ for two days, followed by a standard rehabilitation programme after review of the wound.

During a ten-month period between November 2003 and September 2004, all surviving patients were contacted by telephone by a research physiotherapist (LMGK) with the aim of establishing implant survival. Those who could not be contacted directly were traced through their general practitioner. In the case of deceased patients, hospital and general practitioner records were reviewed and relatives were contacted by telephone to ascertain the survival of the implant. The interval of follow-up was recorded as the interval between the date of the operation and the date of either the death of the patient or confirmation of the survival of the implant.

Statistical analysis. We used life-table analysis, as detailed by Armitage and Berry. ${ }^{9}$ Asymmetrical binomial confidence intervals as described by Rothman ${ }^{10}$ were calculated using the 'effective number at risk' method described by Murray, Carr and Bulstrode. ${ }^{11}$ The endpoint (revision) was defined as further surgery, irrespective of indication, that involved replacement of any of the three original components (femoral component, tibial tray, polyethylene insert). A comparison of the cumulative survival rates for the two groups was made using Cox's proportional hazards regression analysis, ${ }^{9}$ with operation, gender, age, diagnosis and operative side as covariates. Statistical significance was set at $\mathrm{p}<0.05$. 


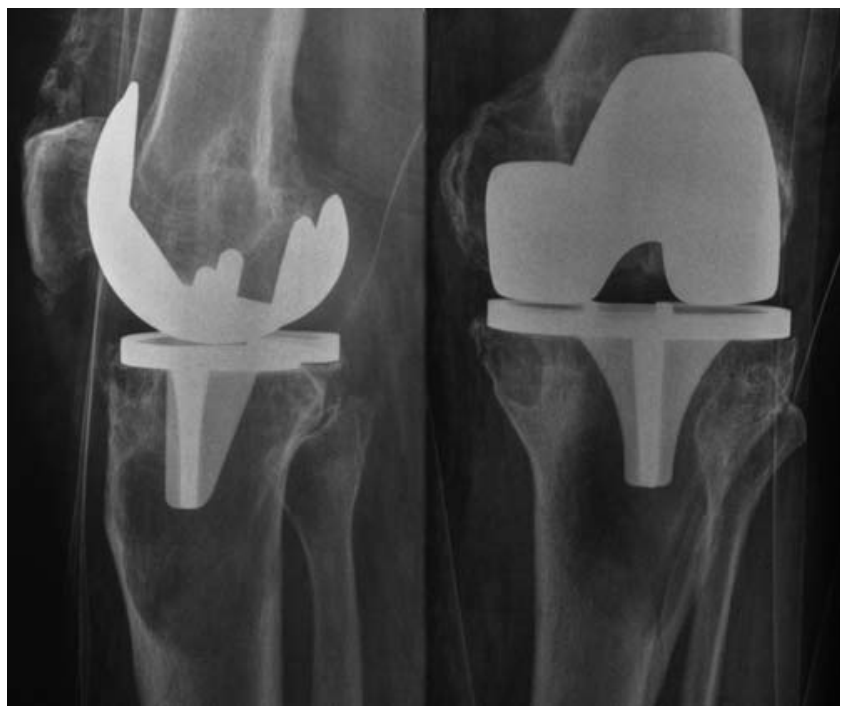

Fig. 1

Radiographs of a cementless total knee replacement showing gross osteolysis prior to revision.

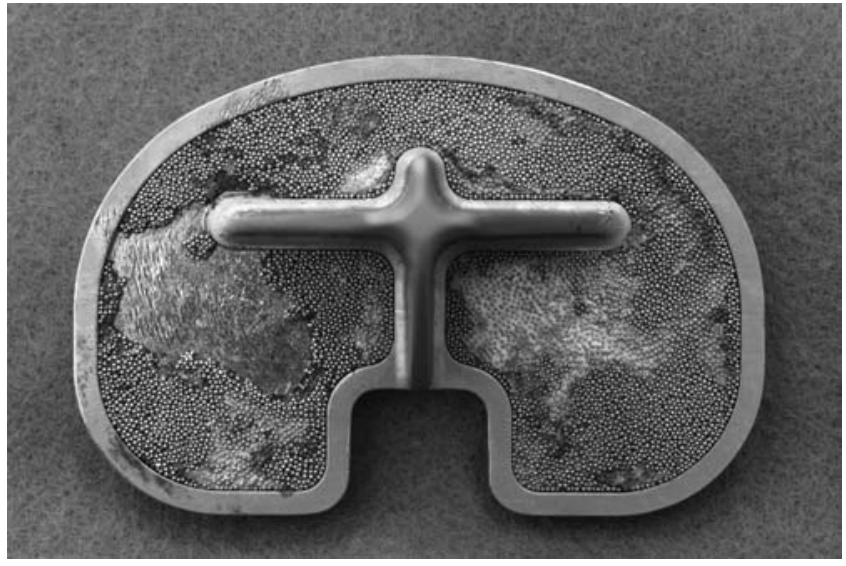

Fig. 2

Photograph of an explanted cementless prosthesis showing debonding of the porous-bead coating.

\section{Results}

At the last review 97 patients (126 knees) in the cemented group and 85 (106 knees) in the cementless group had died. In addition, two cementless implants had been lost because of above-knee amputation, one after fracture of the femur and one for gangrene secondary to diabetes mellitus. For the purpose of life-table survival analysis, both of these patients were withdrawn from the series, which is equivalent to the loss of an implant due to death. All 214 surviving patients (269 knees) were contacted, with no loss to followup. The survival of the implants was ascertained at a mean
Table III. Anderson Orthopaedic Research Institute (AORI) grades for 13 of the 26 knees revised for aseptic loosening

\begin{tabular}{cll}
\hline AORI grade & Cemented $(\mathbf{n}=5)$ & Cementless $(\mathbf{n}=8)$ \\
\hline Tibial & 3 & 2 \\
1 & 1 & - \\
$2 \mathrm{a}$ & 1 & 4 \\
$2 \mathrm{~b}$ & - & 2 \\
3 & &
\end{tabular}

Femoral

$\begin{array}{lll}1 & 1 & 1 \\ 2 a & 1 & - \\ 2 b & 3 & 6 \\ 3 & - & 1\end{array}$

* Grade 1: Intact and full metaphyseal bone and flare. No component subsidence or osteolysis. Intra-operatively: No augments (> $4 \mathrm{~mm}$ ), structural grafts, or $>1 \mathrm{~cm}$ cement fill required

Grade 2: Damaged metaphysis, shortened metaphyseal flare. Intraoperatively: Joint line restored with either an augmented component (>4 $\mathrm{mm}$ ), particulate autograft or allograft, or $>1 \mathrm{~cm}$ fill. (One condyle $=$ grade $2 \mathrm{a}$, both condyle $=$ grade $2 \mathrm{~b}$ )

Grade 3: Deficient metaphyseal segment. Intra-operatively: Need to reconstruct condyle or plateau with structural graft, augment, cement or hinged components

follow-up of 8.9 years (5.8 to 16.8 ) in the cemented group and 8.7 years $(6.9$ to 16.6$)$ in the cementless group.

A total of 54 of 501 knees $(10.8 \%)$ required further surgery, 27 of $277(9.7 \%)$ in the cemented group and 27 of $224(12.1 \%)$ in the cementless group. Of these reoperations, 44 were revision procedures (24 of 277 (8.7\%) cemented $v$ s 20 of 224 (8.9\%) cementless). In the cemented group components were revised for infection in seven patients $(2.5 \%)$, for aseptic loosening in $14(5 \%)$, for polyethylene wear debris in one $(0.4 \%)$, and for exchange of polyethylene insert during a procedure for patellar realignment in two $(0.7 \%)$. Patellar resurfacing was undertaken for anterior knee pain in three cases; these patients were not included as revisions, as the original components were not revised. In the cementless group, components were revised for infection in four patients $(1.8 \%)$, for aseptic loosening in $12(5.4 \%)$, for instability in two $(0.9 \%)$, and for exchange of polyethylene insert during a proceedure for anterior knee pain in two $(0.9 \%)$. A further seven operations were not included as revisions. Patellar resurfacing was undertaken for anterior knee pain in four cases. Proven infection was successfully treated by arthrotomy, lavage and systemic antibiotics in two knees without loss of the components, and secondary patellar realignment was undertaken in one. At the time of follow-up seven patients were awaiting revision surgery for aseptic loosening (four cemented and three cementless).

Of the 26 revisions performed for aseptic loosening additional information was available for 13 procedures (five cemented, eight cementless) performed by one of the authors (CNAE). At the time of revision there was no difficulty in removing the components, irrespective of the method of fixation. Cementless fixation was associated 
Table IV. Life-table analysis of cemented press-fit condylar total knee replacements with revision for all causes as the endpoint (no patients were lost to follow up)

\begin{tabular}{|c|c|c|c|c|c|c|c|c|c|}
\hline $\begin{array}{l}\text { Years since } \\
\text { operation }\end{array}$ & $\begin{array}{l}\text { Number } \\
\text { at start }\end{array}$ & $\begin{array}{l}\text { Number } \\
\text { revised }\end{array}$ & Withdrawn & $\begin{array}{l}\text { Number at } \\
\text { risk }\end{array}$ & $\begin{array}{l}\text { Effective } \\
\text { number at } \\
\text { risk }\end{array}$ & $\begin{array}{l}\text { Annual } \\
\text { failure rate } \\
(\%)\end{array}$ & $\begin{array}{l}\text { Annual } \\
\text { success rate } \\
(\%)\end{array}$ & $\begin{array}{l}\text { Survival rate } \\
(\%)\end{array}$ & $\begin{array}{l}95 \% \\
\text { confidence } \\
\text { interval }\end{array}$ \\
\hline 0 to 1 & 277 & 2 & 5 & 274.5 & 274.5 & 0.7 & 99.3 & 99.3 & 97.4 to 99.8 \\
\hline 1 to 2 & 270 & 3 & 9 & 269.5 & 269.9 & 1.1 & 98.9 & 98.1 & 95.7 to 99.2 \\
\hline 2 to 3 & 258 & 1 & 7 & 254.5 & 264.6 & 0.4 & 99.6 & 97.8 & 95.2 to 99.0 \\
\hline 3 to 4 & 250 & 0 & 11 & 244.5 & 259.3 & 0.0 & 100.0 & 97.8 & 95.1 to 99.0 \\
\hline 4 to 5 & 239 & 0 & 9 & 234.5 & 253.9 & 0.0 & 100.0 & 97.8 & 95.1 to 99.0 \\
\hline 5 to 6 & 230 & 0 & 21 & 219.5 & 247.4 & 0.0 & 100.0 & 97.8 & 95.1 to 99.0 \\
\hline 6 to 7 & 209 & 2 & 12 & 203.0 & 239.9 & 1.0 & 99.0 & 96.8 & 93.7 to 98.4 \\
\hline 7 to 8 & 195 & 4 & 28 & 181.0 & 230.5 & 2.2 & 97.8 & 94.7 & 91.0 to 96.9 \\
\hline 8 to 9 & 163 & 1 & 28 & 149.0 & 217.3 & 0.7 & 99.3 & 94.0 & 90.1 to 96.5 \\
\hline 9 to 10 & 134 & 3 & 23 & 122.5 & 201.7 & 2.4 & 97.6 & 91.7 & 87.1 to 94.8 \\
\hline 10 to 11 & 108 & 1 & 18 & 99.0 & 184.3 & 1.0 & 99.0 & 90.8 & 85.8 to 94.2 \\
\hline 11 to 12 & 89 & 1 & 22 & 78.0 & 165.5 & 1.3 & 98.7 & 89.6 & 93.4 to 84.1 \\
\hline 12 to 13 & 66 & 3 & 16 & 58.0 & 144.9 & 5.2 & 94.8 & 85.0 & 78.3 to 89.9 \\
\hline 13 to 14 & 47 & 2 & 15 & 39.5 & 121.7 & 5.1 & 94.9 & 80.7 & 72.8 to 86.7 \\
\hline 14 to 15 & 30 & 0 & 16 & 22.0 & 93.5 & 0.0 & 100.0 & 80.7 & 71.5 to 87.4 \\
\hline 15 to 16 & 14 & 0 & 9 & 9.5 & 60.2 & 0.0 & 100.0 & 80.7 & 69.0 to 88.7 \\
\hline 16 to 17 & 5 & 1 & 4 & 3.0 & 26.7 & 33.3 & 66.7 & 53.8 & 35.6 to 71.0 \\
\hline
\end{tabular}

Table V. Life-table analysis of cementless press-fit condylar total knee replacements with revision for all causes as the endpoint (no patients were lost to follow-up)

\begin{tabular}{|c|c|c|c|c|c|c|c|c|c|}
\hline $\begin{array}{l}\text { Years since } \\
\text { operation }\end{array}$ & $\begin{array}{l}\text { Number at } \\
\text { start }\end{array}$ & $\begin{array}{l}\text { Number } \\
\text { revised }\end{array}$ & Withdrawn & $\begin{array}{l}\text { Number at } \\
\text { risk }\end{array}$ & $\begin{array}{l}\text { Effective } \\
\text { number at } \\
\text { risk }\end{array}$ & $\begin{array}{l}\text { Annual } \\
\text { failure rate } \\
(\%)\end{array}$ & $\begin{array}{l}\text { Annual } \\
\text { success rate } \\
(\%)\end{array}$ & $\begin{array}{l}\text { Survival rate } \\
(\%)\end{array}$ & $\begin{array}{l}95 \% \\
\text { confidence } \\
\text { interval }\end{array}$ \\
\hline 0 to 1 & 224 & 1 & 10 & 219.0 & 219.0 & 0.5 & 99.5 & 99.5 & 97.5 to 99.9 \\
\hline 1 to 2 & 213 & 3 & 7 & 209.5 & 214.1 & 1.4 & 98.6 & 98.1 & 95.3 to 99.3 \\
\hline 2 to 3 & 203 & 1 & 3 & 201.5 & 209.8 & 0.5 & 99.5 & 97.6 & 94.6 to 99.0 \\
\hline 3 to 4 & 199 & 0 & 7 & 195.5 & 206.0 & 0.0 & 100.0 & 97.6 & 94.5 to 99.0 \\
\hline 4 to 5 & 192 & 0 & 8 & 188.0 & 202.1 & 0.0 & 100.0 & 97.6 & 94.5 to 99.0 \\
\hline 5 to 6 & 184 & 0 & 11 & 178.5 & 197.8 & 0.0 & 100.0 & 97.6 & 94.4 to 99.0 \\
\hline 6 to 7 & 173 & 1 & 13 & 166.5 & 192.6 & 0.6 & 99.4 & 97.0 & 93.6 to 98.7 \\
\hline 7 to 8 & 159 & 2 & 26 & 146.0 & 185.2 & 1.4 & 98.6 & 95.7 & 91.8 to 97.8 \\
\hline 8 to 9 & 131 & 2 & 17 & 122.5 & 175.2 & 1.6 & 98.4 & 94.2 & 89.6 to 96.8 \\
\hline 9 to 10 & 112 & 1 & 11 & 106.5 & 164.6 & 0.9 & 99.1 & 93.3 & 88.4 to 96.2 \\
\hline 10 to 11 & 100 & 3 & 23 & 88.5 & 152.7 & 3.4 & 96.6 & 90.1 & 84.3 to 93.9 \\
\hline 11 to 12 & 74 & 2 & 26 & 61.0 & 135.7 & 3.3 & 96.7 & 87.2 & 80.5 to 91.8 \\
\hline 12 to 13 & 46 & 2 & 17 & 37.5 & 112.9 & 5.3 & 94.7 & 82.5 & 74.5 to 88.4 \\
\hline 13 to 14 & 27 & 2 & 8 & 23.0 & 88.3 & 8.7 & 91.3 & 75.3 & 65.4 to 83.1 \\
\hline 14 to 15 & 17 & 0 & 8 & 13.0 & 63.7 & 0.0 & 100.0 & 75.3 & 63.5 to 84.3 \\
\hline 15 to 16 & 9 & 0 & 7 & 5.5 & 38.3 & 0.0 & 100.0 & 75.3 & 59.8 to 86.2 \\
\hline 16 to 17 & 2 & 0 & 2 & 1.0 & 11.3 & 0.0 & 100.0 & 75.3 & 46.2 to 91.6 \\
\hline
\end{tabular}

with significant osteolysis (Fig. 1) and debonding of the porous-bead coating (Fig. 2), and there was a fibrous layer below the tibial component in all cases. The only place where the femoral components were well-fixed, if anywhere, was anteriorly. In both cemented and cementless fixation there was a significant loss of bone from the posterior femoral condyles. The bone loss has been graded according to Anderson Orthopaedic Research Institute grades ${ }^{12}$ for these 13 revisions (Table III).

Survival analysis used revision surgery, with exchange of any of the three originally inserted components (femoral, tibial, polyethylene insert), as the endpoint. Life-table analysis (Tables IV and V) showed a 15-year survival of
$80.7 \%$ (95\% confidence interval (CI) 71.5 to 87.4 ) for cemented knees, with a ten-year survival of $91.7 \%$ (95\% CI 87.1 to 94.8$)$. For cementless knees 15 -year survival was $75.3 \%$ (95\% CI 63.5 to 84.3 ), with a ten-year survival of 93.3\% (95\% CI 88.4 to 96.2 ). Figures 3 and 4 show the respective survival curves. Although the 15 -year survival for cementless knees was lower, Cox's analysis showed no apparent difference in the hazard of failure between the two groups (hazard ratio $(\mathrm{HR})=0.83(95 \% \mathrm{CI} 0.45$ to 1.52$)$, $\mathrm{p}=0.55)$.

The life tables in this analysis differ considerably from those seen in our previous ten-year analysis ${ }^{6}$ reflecting the longer follow-up. At the time of the previous analysis the 


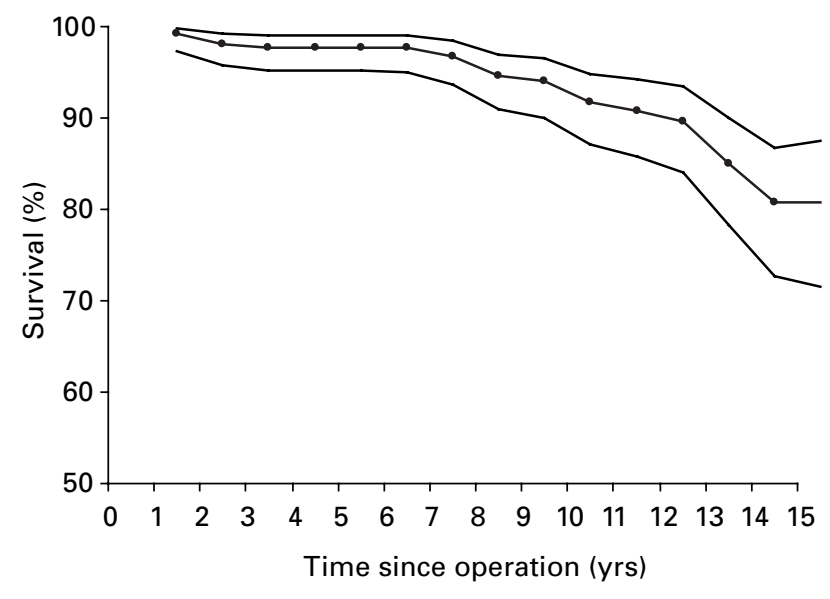

Fig. 3

Survival curve with binomial 95\% confidence intervals for cemented press-fit condylar total knee replacement with revision for all causes as the endpoint.

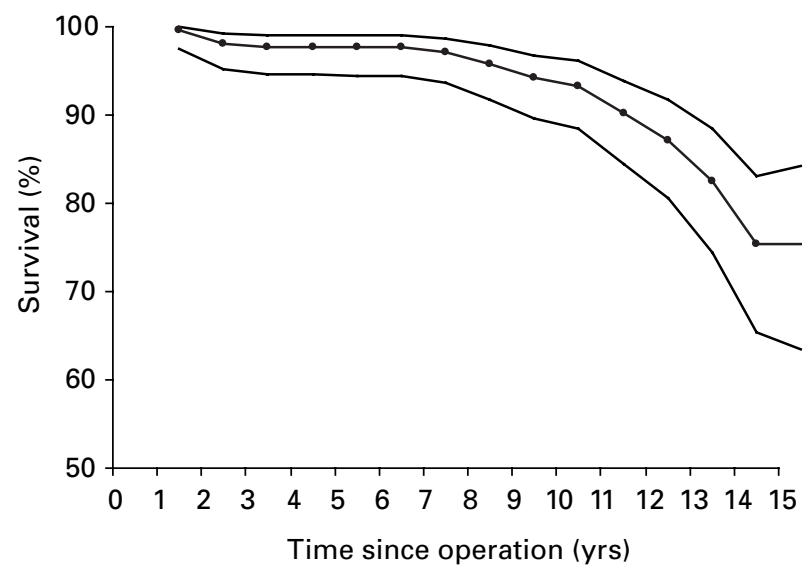

Fig. 4

Survival curve with binomial 95\% confidence intervals for cementless press-fit condylar total knee replacement with revision for all causes as the endpoint.

minimum follow-up was 2.7 years and in the current analysis the minimum follow-up is 5.8 years. This explains why differences are observed from the third year of the life table onwards in the current study.

When comparing the covariates (side of operation, age, diagnosis, gender), there was no significant difference between the side of operation $(\mathrm{HR}=0.58(95 \% \mathrm{CI} 0.32$ to $1.05), \mathrm{p}=0.07)$, age $(\mathrm{HR}=0.97(95 \% \mathrm{CI} 0.92$ to 1.01$)$, $\mathrm{p}=0.10$ ), or diagnosis (osteoarthritis vs non-osteoarthritis, $\mathrm{HR}=1.25(95 \%$ CI 0.38 to 4.12$), \mathrm{p}=0.72)$. However, there was a significant gender difference (males $v$ s females, $\mathrm{HR}=2.48(95 \%$ CI 1.34 to 4.61$), \mathrm{p}=0.004)$, more males having a revision following a cemented procedure than after cementless procedure (16 vs 12 revisions). In comparison, the female patients had the same number of revisions in both the cemented and cementless groups (eight in each group).

In the 'worst-case scenario' including seven patients awaiting revision, the 15 -year survival for the cemented group was $78.3 \%$ (95\% CI 68.9 to 85.4 ) and $72.0 \%$ (95\% CI 59.9 to 81.5 ) for the cementless group.

\section{Discussion}

The study reports the long-term survival of the PCL-sparing knee prosthesis at 15 years. Using revision surgery that involved replacement of any of the three original components irrespective of indication as the endpoint, the 15-year survival rates were $80.7 \%$ and $75.3 \%$ in the cemented and cementless groups, respectively.

A total of 44 knees $(8.8 \%)$ required revision surgery. The indication for the majority of revision procedures was aseptic loosening, which occurred in 26 revisions $(59.1 \%)$. Overall, the indications for revision between the two groups were comparable. This is in contrast to our ten-year analysis, where the indications for many of the revision procedures was infection. ${ }^{6}$ At the time of the ten-year analysis only four implants had been revised for aseptic loosening.

Our 15-year survival rate is comparable to those in other reports of longer term survival of cemented TKRs. Rates of survival of $87 \%$ at 12 years $^{13}$ and $82 \%$ at 14 years ${ }^{14}$ have been reported for the Kinematic Condylar Knee (Howmedica, Rutherford, New Jersey), $87 \%$ at 13 years $^{15}$ for the Kinematic Stabiliser (Howmedica), and $96.9 \%$ at 14 years $^{16}$ for the Anatomical Graduated Components (Biomet Inc., Warsaw, Indiana). In these series, loss to follow-up ranged from $1 \%$ to $8.2 \%$. A worst-case analysis performed on the total condylar posterior stabilised prosthesis (Johnson \& Johnson, New Brunswick, New Jersey) reported a 14 -year survival of $93.1 \%$ for implants with a metal-backed tibia and a 16-year survival of $90.3 \%$ for implants with an all-polyethylene tibia. ${ }^{17}$ A 20-year survival rate of $91.9 \%$ has been reported with the total condylar knee (Johnson \& Johnson). ${ }^{18}$ This series did, however, have a $15.9 \%$ loss to follow-up, which may partly explain this high rate of survival.

There are relatively few longer term survival rates for cementless prostheses in the literature. A few series have reported ten-year survival, with rates including $93.4 \%$ for the natural knee (Zimmer Inc, Warsaw, Indiana), ${ }^{19} 97 \%$ for the anatomical graduated components (Biomet Inc.) ${ }^{20}$ and $94 \%$ for the Ortholoc I (Biomet Inc.). ${ }^{21}$ One series ${ }^{22}$ reported a 13 -year survival rate of $96.7 \%$ with the Osteonics knee (Stryker, Mahwah, New Jersey), but this was from a small series with a $9.2 \%$ loss to follow-up. A survivorship of $93 \%$ at 13 years has also been reported using the hydroxyapatite (HA)-coated Insall Burstein II TKR ${ }^{23}$ (Cremascoli Fry Ortho Ltd., Surrey, United Kingdom). Epinette 
and Manley ${ }^{24}$ assessed the longer term survival of the partially HA-coated Omnifit knee prosthesis Series 3000 (Stryker) and the fully HA-coated series 7000 (Stryker). At 11 years, the cumulative survival, using retrieval for any cause as the endpoint, was $94.1 \%$ and $94.4 \%$ in the two respective groups. These results are comparable with our ten-year survival rate of $93.3 \%$.

Many survival analyses of TKR include a number of patients who have been lost to follow-up. This can lead to overestimation of the true survival rate. ${ }^{25}$ In the previously mentioned series, ${ }^{13-22}$ loss to follow-up ranged between $1 \%$ and $15.9 \%$. This is possibly why our longer term survival seems to be lower than previously reported rates. In our series, owing to the prospective design there was no loss to follow-up. Our reported survival rates should therefore be an accurate reflection of the expected survival of the PFC replacement at 15 years.

In this series there was no significant difference between the survival rates for cemented and cementless fixation. This is in keeping with the findings from our earlier tenyear analysis. ${ }^{6}$ Longer term comparative studies of cemented and cementless fixation for knee replacement have suggested that cementless implantation is associated with a poorer survival and clinical outcome. A retrospective case-matched series undertaken by Duffy et al ${ }^{5}$ reported survival rates of $94.2 \%$ and $72.7 \%$ at ten years for cemented and cementless fixation, respectively. However, the groups contained small numbers and were poorly matched, especially with regard to age, the cementless group being approximately ten years younger. Chockalingham and $S \operatorname{cott}^{2}$ compared cemented and cementless fixation of the femoral component of the Freeman-Samuelson prosthesis and found a significant difference in the results at six years when the failure rates were $0.6 \%$ and $9.8 \%$ for cemented and cementless fixation, respectively. This series was a non-randomised design, had unequal group sizes, and it is not clear to what extent the groups were matched for age, gender and underlying diagnosis. This makes it difficult to interpret the findings. Nafei et $\mathrm{al}^{4}$ found a higher revision rate in a small cohort of patients who underwent cementless TKR fixation compared with cemented fixation. They also found that patients who had cementless fixation were more likely to have residual pain $(24 \%$ vs $4 \%)$. Improved clinical results with cemented over cementless fixation have also been described by Rorabeck et al. ${ }^{3}$ Unlike ours, their study used two different designs of implant, which could partly account for their findings.

In this analysis the ten-year survival rates were $91.7 \%$ and $93.3 \%$ for cemented and cementless knees, respectively. These rates are lower than those reported in our previous paper, ${ }^{6}$ when the survival rates were $95.3 \%$ and $95.6 \%$. It is assumed that the observed decrease is a function of the longer follow-up in this current study, in which a larger proportion of the original cohort had reached ten years. The results reported in this paper are therefore a more accurate reflection of the ten-year survival rates for the different methods of fixation of this implant.

One limitation with this study was our inability to collect more clinical information, including data relating to patient outcome measures of pain and functional limitation. Although this would have provided useful additional data, the current study was undertaken with the sole aim of establishing and analysing the 15-year survival of the PFC TKR. We recognise that survival data are the measure most likely to be applied if the National Institute for Clinical Excellence were to develop guidance for TKR surgery as it has for total hip replacement.

This study provides surgeons with reliable longer term data for the revision rates of the most commonly-used TKR. It demonstrates that the survival of the press-fit condylar TKR remains good at 15 years, irrespective of the method of fixation in this series where randomisation of fixation was delayed until the suitability of either method of fixation was confirmed after preparation of the bone.

\section{Supplementary material}

$\dddot{2}$ Tables showing details of the revisions and reoperations in both the cemented and cementless groups are available with the electronic version of this article on our website at www.jbjs.org.uk

The author or one or more of the authors have received or will receive benefits for personal or professional use from a commercial party related directly or indirectly to the subject of this article.

\section{References}

1. No authors listed. National Joint Registry for England and Wales: Summary of the 2nd Annual Report. www.njrcentre.org.uk (date last accessed 6 August 2007).

2. Chockalingham S, Scott G. The outcome of cemented vs cementless fixation of a femoral component in total knee replacement (TKR) with the identification of radiological signs for the prediction of failure. Knee 2000;7:233-8.

3. Rorabeck CH, Bourne RB, Nott L. The cemented kinematic II and the noncemented porous coating anatomic prostheses for total knee replacement: a prospective evaluation. J Bone Joint Surg [Am] 1988;70-A:483-90.

4. Nafei A, Nielsen S, Kristensen 0, Hvid I. The press-fit kinemax knee arthroplasty: high failure rate of non cemented implants. J Bone Joint Surg [Br] 1992;74B:243-6.

5. Duffy GP, Berry DJ, Rand JA. Cement versus cementless fixation in total knee arthroplasty. Clin Orthop 1998;356:66-72.

6. Khaw FM, Kirk LMG, Morris RW, Gregg PJ. A randomised, controlled trial of cemented versus cementless press fit condylar total knee replacement: ten-year survival analysis. J Bone Joint Surg [Br] 2002;84-B:658-66.

7. Begg C, Cho M, Eastwood S, et al. Improving the quality of reporting of randomised controlled trials: the CONSORT statement. JAMA 1996;276:637-9.

8. Brodell JD, Axon DL, Evarts CM. The Robert Jones bandage. J Bone Joint Surg [Br] 1986;68-B:776-9.

9. Armitage P, Berry G. Statistical methods in medical research. Third ed. Oxford: Blackwell Scientific Publications, 1994.

10. Rothman KJ. Estimation of confidence limits for the cumulative probability of survival in life table analysis. J Chronic Dis 1978;31:557-60

11. Murray DW, Carr AJ, Bulstrode C. Survival analysis of joint replacement. J Bone Joint Surg [Br] 1993;75-B:697-704

12. Engh CA, Ammeen DJ. Bone loss with revision total knee arthroplasty: defect classification and alternatives for reconstruction. AAOS Instr Course Lect 1999;48:167-75.

13. Weir DJ, Moran CG, Pinder IM. Kinematic condylar total knee arthroplasty: 14 year survivorship analysis of 208 consecutive cases. J Bone Joint Surg [Br] 1996;78B:907-11. 
14. van Loon CJM, Wisse MA, de Waal Malefijit MC, Jansen RH, Veth RPH. The kinematic total knee arthroplasty: a 10- to 15-year follow-up and survival analysis. Arch Orthop Trauma Surg 2000;120:48-52

15. Emmerson KP, Moran CG, Pinder IM. Survivorship analysis of the kinematic stabilizer total knee replacement: a 10- to 14-year follow-up. J Bone Joint Surg $[\mathrm{Br}]$ 1996;78-B:441-5.

16. Worland RL, Johnson G, Alemparte J, et al. Ten to fourteen year survival and functional analysis of the AGC total knee replacement system. Knee 2002;9:133-7.

17. Font-Rodriguez DE, Scuderi GR, Insall JN. Survivorship of cemented total knee arthroplasty. Clin Orthop 1997;345:79-86.

18. Ma HM, Lu YC, Ho FY, Huang CH. Long-term results of total condylar knee arthroplasty. J Arthroplasty 2005;20:580-4.

19. Hofmann AA, Evanich JD, Ferguson RP, Camargo MP. Ten- to 14-year clinical followup of the cementless Natural Knee system. Clin Orthop 2001;388:85-94.
20. Schroder HM, Berthelsen MD, Hassani G, Hansen EB, Solgaard S. Cementless porous-coated total knee arthroplasty: 10 year results in a consecutive series. Arthroplasty 2001;16:559-67.

21. Whiteside LA. Cementless total knee replacement: nine- to 11-year results and 10year survivorship analysis. Clin Orthop 1994;309:185-9.

22. Watanabe H, Akizuki S, Takizawa T. Survival analysis of a cementless, cruciateretaining total knee arthroplasty: clinical and radiographic assessment 10 to 13 years after surgery. J Bone Joint Surg [Br] 2004;86-B:824-9.

23. Oliver MC, Keast-Butler OD, Hinves BL, Sheppard JAN. A hydroxyapatitecoated Insall Burstein II total knee replacement: Il-year results. J Bone Joint Surg [Br] 2005;87-B:478-82.

24. Epinette JA, Manley MT. Hydroxyapatite coated total knee replacement: clinical experience at 10 to 15 years. J Bone Joint Surg [Br] 2007;89-B:34-8.

25. Murray DW, Britton AR, Bulstrode CJK. Loss to follow-up matters. J Bone Joint Surg [Br] 1997;79-B:254-7. 